\title{
The Dynamics of Energy Poverty: Evidence from Spain
}

\author{
EUAN PHIMISTER, ${ }^{\mathrm{a}, *}$ ESPERANZA VERA-TOSCANO, $^{\mathrm{b}}$ and DEBORAH ROBERTS ${ }^{\mathrm{a}, \mathrm{c}}$
}

\begin{abstract}
ABS TRACT
Reducing the proportion of households defined as energy poor is an increasingly important policy objective. This paper uses longitudinal data to examine the level and dynamics of energy poverty in Spain, comparing the results to the level and dynamics of income poverty. Two alternative measures of energy poverty are used in the analysis-one based on energy expenditure, the other reflecting an individual's perceptions of difficulty in heating their home, paying utility bills and housing condition. The proportion of those in income poverty and also in energy poverty is relatively low suggesting a need for specific as opposed to general measures to address the latter. In relation to the dynamics of energy poverty, at the aggregate level there is a substantially greater movement out of expenditure-based energy poverty relative to subjective energy poverty and income poverty while the rate of re-entry into poverty was highest for the subjective energy poverty measure. The analysis also provides evidence of duration dependence in energy poverty. The results show clearly how mitigating expenditure behaviour reduces the level and alters the dynamics of expenditure-based energy poverty compared to subjective energy poverty. The implications for designing, targeting and monitoring energy policy are considered.
\end{abstract}

Keywords: energy poverty dynamics, income poverty, energy policy, longitudinal data

http://dx.doi.org/10.5547/2160-5890.4.1.ephi

\section{* 1. INTRODUCTION}

Recent empirical research has highlighted energy poverty as a problem in a range of EU countries (Bouzarovski et al. 2012; Dubois and Mayer, 2013; Healy and Clinch, 2002). In Spain, estimates suggest that approximately 10 per cent of households (equivalent to 4 million people) were in energy poverty in 2010 (Tirado Herrero et al., 2012a), with the winter mortality rate in Spain among the highest in Europe (Healy, 2003). Within this context, reducing the proportion of households defined as energy poor has become an important policy objective at the EU level with Directives 2009/72/EC and 2009/73/EC requiring all member states to develop policies in this area. This, in turn requires a better understanding of the nature of energy poverty.

\footnotetext{
${ }^{a}$ Aberdeen Centre for Research in Energy Economics and Finance, Business School, University of Aberdeen, Aberdeen, United Kingdom. E-mail: e.phimister@abdn.ac.uk. Tel +441224273855

b Instituto de Estudios Sociales Avanzados (IESA), Consejo Superior de Investigaciones Científicas (CSIC) Córdoba, Spain. Email: esperanza.vera@csic.es

${ }^{c}$ Social, Economic and Geographical Sciences group, James Hutton Institute, United Kingdom. E-mail: deb.roberts@hutton.ac.uk.

* Corresponding author. E-mail: e.phimister@abdn.ac.uk. Tel +44 1224273855

Economics of Energy \& Environmental Policy, Vol. 4, No. 1. Copyright (C) 2015 by the IAEE. All rights reserved.
} 
While there have been a number of previous studies focussed on measuring and explaining the level of energy poverty at a point in time (Boardman, 1991; EPEE, 2009; Healy and Clinch, 2002; 2004; Hills, 2002), to the authors' knowledge there has been no empirical work considering the dynamics of energy poverty. Assuming the aim of policy is to make households more resilient in the face of rising energy costs, understanding of the routes into and out of energy poverty is clearly useful information. Further, it would be helpful to know how energy poverty is distinct from income poverty, therefore justifying the need (or otherwise) for separate policy measures and priorities.

Hills (2012) emphasizes the particular vulnerability of energy poor households arising from poor energy efficiency in their homes which they cannot change due to high capital costs. He argues that individuals in such households live in lower temperatures and are thus more vulnerable to ill-health and other negative social outcomes. While the causality is difficult to establish, evidence does show that living at low-temperature is associated with a higher prevalence of certain diseases and health problems (Morrison and Short, 2008; Roberts, 2008) and that these problems particularly affect vulnerable populations such as the elderly and children (Garbino, 2004; Howieson, 2005; Liddell and Morris, 2010). If the energy poor are also income poor, entry into and exit from energy poverty may be associated with similar events to income poverty, namely changes in labour income and labour market status, household composition etc. (Jenkins and Rigg, 2001). However, the dynamics of energy poverty may differ from income poverty for a variety of reasons. First, investment in improved energy efficiency measures, either by households or via government programmes (for example requiring buildings to be of Passivhaus standard), may move individuals out of energy poverty but not income poverty. More generally, factors such as variations in winter temperatures or changes in energy prices can significantly affect energy poverty at a point in time but not income poverty which is defined in such a way as to be independent from the cost of living. Finally, energy poverty may be more pervasive with a larger number and wider variety of households affected. In this case, specific policies for energy poverty are required.

Against this background, this paper considers both the level and dynamics of energy poverty in Spain and compares them with the level and dynamics of income poverty. To do this we use longitudinal information from the Survey on Income and Living Conditions for Spain (2007-2010). Two measures of energy poverty are considered in the analysis, one expenditure-based (Boardman, 1991), the other subjective, relating to the self-reported perception of individuals (Healy and Clinch, 2002; 2004). Recent research by Waddams Price et al., (2012) has explored the relationship between expenditure-based and subjective measures and shows that, although related, the relationship is complex. They argue for the wider use of subjective energy poverty measures by policy makers as they appear to capture a number of aspects of energy poverty which expenditure-based measures may miss.

There are a number of potential reasons why the dynamics of energy poverty might differ depending on the measure used. If, for example, energy prices rise or climate worsens, the extent of entry into subjective energy poverty is expected to be greater than that observed through expenditure-based measures as some households' "ration their energy consumption" or, in other words, take mitigating actions. Similarly, mobility out of energy poverty would be expected to be greater for the expenditure-based measure than the subjective measure again due to adjustments in behaviour. In contrast, subjective energy poverty measures are expected to be more stable over time and have exit and entry rates more similar to those of income poverty. We therefore systematically consider and compare both measures in the analysis below. 
For the income poverty measure we use a standard income threshold for classifying individuals as being in poverty. Having first explored the level of each type of poverty and the relationship between them, we then analyze the transitions into and out of energy poverty by applying a range of techniques applied in the analysis of the dynamics of poverty (e.g. Jarvis and Jenkins 1997, Phimister et al. 2000; Stevens, 1999).

The plan of the paper is as follows. Section 2 discusses the energy and income poverty definitions used in the analysis. Section 3 describes the Survey on Income and Living Conditions for Spain in more detail and reports various descriptive statistics including an analysis of the extent of overlap between those in the sample who are energy poor and those who are income poor. Section 4 provides an aggregate level analysis of the dynamics of energy poverty under the two definitions considered and contrasts it to that of income poverty. Here, the longitudinal information on individuals is used to construct a Markov matrix that traces movements between energy poverty categories over the four years available. Section 5 further exploits the dynamic information to provide a more detailed picture of the degree of heterogeneity of those experiencing energy poverty by detailing the distribution of energy poverty spells and the characteristics of those who experienced energy poverty 'temporarily' and 'persistently' during the four-year period. Using individual spells in (and out of) energy and income poverty, we also report life-table estimates of the survivor function associated with spells in a particular state. This enables us to show how the probability of an energy poverty exit (or re-entry) depends on the number of periods spent in energy poverty. Section 6 concludes.

\section{* 2. DISTINGUISHING ENERGY POVERTY FROM INCOME POVERTY}

There is a general consensus that, conceptually, energy poor households are those who are unable to adequately heat their homes (Hills, 2012). ${ }^{1}$ How does this differ from households being classified as income poor? Clearly low incomes play a role in determining whether or not a household is energy poor. However energy poverty is distinct in so far that it may reflect heating inadequacy and energy inefficiency associated with a household's place of residence (Moore, 2012). As such energy poverty in developed countries involves a "complex interaction of low income and energy efficiency" (Healy and Clinch, 2002), with energy prices, individual energy needs and climatic conditions important components (Boardman, 2012; Bouzarovski et al, 2012; Liddell et al, 2012). In developing countries energy poverty is often also framed in terms of access to different energy sources (Pachauri and Spreng, 2004).

While there is consensus around the concept, there is no single accepted definition of how to identify individuals in energy poverty. In her original work, Boardman (1991) defined energy poverty in terms of an energy expenditure threshold with households who were spending $10 \%$ of their income on energy within the home classified as energy poor. Ten percent was selected as the threshold on the basis that this was approximately twice the median level of energy expenditure. Many European countries continue to use the percentage of household expenditure on energy as an "objective" definition of energy poverty, with the threshold again often justified (or related) to household energy spending being over two times the median value (EC, 2010; Liddell et al, 2012; Dubois, 2012, 2013). ${ }^{2}$

1. Here, consistent with a range of authors the terms energy and fuel poverty are used interchangeably (Bouzarovski et al 2012).

2. For example, a threshold of 10 percent expenditure on energy consumption for the home provides the basis for the official French definition of "energie précarité". 
However expenditure-based measures of energy poverty have been criticized for the fact that they mask households facing difficulty in heating their homes but who reduce their energy spending (Healy and Clinch, 2004; Hills, 2012; Brunner et al., 2012). Certainly there is qualitative evidence that suggests that households at risk of energy poverty adopt a variety of coping strategies which reduce expenditure, e.g. heating a single room, increasing clothing worn, spending more time in bed, reducing lighting (Brunner et al, 2012). In response to this, an alternative definition of energy poverty was developed in the UK to capture a household's required spending based on the energy efficiency of the home rather than actual spending (DoE, 1996). While conceptually stronger, the lack of housing condition data has meant that such a definition has been difficult to implement beyond the UK (Moore, 2012).

An alternative approach has been to define energy poverty using a series of measures based around the individual's self-reported perception of difficulty in heating the home, in paying utility bills, and house conditions (Healy and Clinch, 2002). Recent research shows that the overlap between the two types of measures can be quite limited and that the subjective energy poverty measure captures aspects of energy poverty which expenditure-based measures miss (Waddams Price et al., 2012). In particular, the subjective measures may potentially catch energy poor households that are "rationing their energy consumption" (Dubois 2012, p109) thus overcoming the problem identified earlier.

In this study, an expenditure-based energy poverty measure is used based on household expenditures on gas and electricity as a proportion of net household income (excluding housing costs), with an individual considered energy poor if the proportion of household income spent on energy is greater than 10 per cent (Tirado Herrero et al., 2012a). To complement this, we also use a self-reported subjective measure of energy poverty which relies on an individual's own assessment of the household's ability to afford an adequate thermal comfort level in the dwelling. ${ }^{3}$

For income poverty, the standard approach used by policy makers looks at poverty relatively, consistent with the view that 'poverty as absolute is . . inappropriate' (Townsend, 1979, p.38). Hence, an individual is defined as poor if they live in a household whose income falls below some threshold, where the threshold is not defined on the basis of some absolute need but is relative to other households incomes (Piachaud, 1993). While ultimately any threshold is arbitrary, this approach has been applied widely (e.g. Jenkins and Rigg, 2001; O’Higgins et al, 1990). Specifically we use a poverty income threshold to define as poor individuals living in a household with equivalized disposable income below sixty per cent of the median. ${ }^{4}$ This measure is used as a key policy indicator of poverty and social exclusion risk across the EU (OECD, 2008).

\section{* 3. DATA AND SAMPLE STATISTICS}

\subsection{The Survey on Income and Living Conditions}

The data used in the analysis is drawn from the longitudinal sample of the Survey on Living Conditions for Spain (SLC 2007-2010). The SLC is a "rotating panel" survey, where

\footnotetext{
3. Consistent with Healy and Clinch, $(2002,2004)$ the subjective energy poverty measure is based on whether the individual answered yes to any of the following three questions: "Does your dwelling have any leaks, dampness on the walls, floors, ceilings or in the foundations, or rotten floors, windows or door frames?" (House Damp); "Can your household afford to keep the dwelling heated at an appropriate temperature during the winter months? (Adequate heating)" "Were the water, gas, electricity or community cost bills paid late at all in the last 12 months?" (Late payment).

4. This approach assumes income pooling so that household income is attributed to each individual in the household equivalized to adjust for the demographic composition of the household. Here, due to lack of information we use the method applied by the OECD and divide household income by the square root of household size.
} 
TABLE 1

Levels of energy and income poverty, 2007-2010

\begin{tabular}{ccccc}
\hline & 2007 & 2008 & 2009 & 2010 \\
\hline Expenditure-based energy poverty & 331 & 304 & 458 & 549 \\
& $(6.3 \%)$ & $(5.7 \%)$ & $(8.7 \%)$ & $(10.4 \%)$ \\
\hline Subjective energy poverty & 1334 & 1060 & 1234 & 1457 \\
& $(25.3 \%)$ & $(20.1 \%)$ & $(23.4 \%)$ & $(27.7 \%)$ \\
Adequate heating & 356 & 229 & 320 & 338 \\
& $(6.7 \%)$ & $(4.3 \%)$ & $(6.1 \%)$ & $(6.4 \%)$ \\
House damp & 987 & 802 & 944 & 1133 \\
& $(18.7 \%)$ & $(15.2 \%)$ & $(17.9 \%)$ & $(21.5 \%)$ \\
Late payment & 187 & 151 & 193 & 236 \\
& $(3.5 \%)$ & $(2.8 \%)$ & $(3.6 \%)$ & $(4.5 \%)$ \\
\hline Income poverty & 1067 & 1109 & 1200 & 1209 \\
& $(20.3 \%)$ & $(21.1 \%)$ & $(22.8 \%)$ & $(23.0 \%)$ \\
\hline
\end{tabular}

each unit remains in the sample for a maximum of four years. Thus, the total sample is composed of four panel subsamples with, every year, one panel replaced by a new subsample. The survey uses the Spanish census definition for a family dwelling, with the initial sample including all individuals resident in the main family dwelling.

Not all eligible persons respond to the individual questionnaire in all years. Hence, from this data we construct a balanced panel of individuals who remained in the survey in all four years. This provided a total sample of 21048 observations consisting of 2787 women and 2475 men observed over the four year period, 2007-2010.

\subsection{Descriptive Statistics}

Table 1 reports the percentage of individuals that fall in each of the energy and income poverty measures defined for each of the four years considered. The expenditure energy poverty measure implies that around 10 per cent sample were energy poor in 2010. In contrast, a significantly larger proportion of individuals are energy poor in 2010 under the subjective measure, with the overall level driven primarily by whether respondents considered their home to be damp or not. The difference between the two energy measures narrows between 2007 and 2010, which we speculate may be due increasing expenditure on energy (associated with energy prices increases in the period) and, by the end of the period, a small fall in nominal household incomes.

The level of income poverty in the sample is comparable with that found in other studies and reflects the relatively high rates of income poverty in Spain relative to other EU countries. For example, Eurostat estimates report a 23.1 percent poverty rate in Spain for 2007 (relative a EU25 average of 21.6 percent), rising to a 25.5 percent rate in 2010 (relative to 21.7 average for the EU 25).

The incidence of energy poverty in Table 1 is also broadly comparable with previous research (Tirado Herrero et al., 2012a, 2012b; EU Commission, 2010; Thomson and Snell, 2013) which suggests that energy poverty in Spain is significant although slightly below the EU average. In particular, the values reported are consistent with the EU comparative study 
TABLE 2

Relationship between Energy and Income Poverty Measures, 2007-2010

\begin{tabular}{lccc}
\hline & \multicolumn{3}{c}{ Percentage also in } \\
\cline { 2 - 4 } & $\begin{array}{c}\text { Expenditure-based } \\
\text { energy poverty }\end{array}$ & $\begin{array}{c}\text { Subjective energy } \\
\text { poverty }\end{array}$ & Income Poverty \\
\hline Expenditure-based energy poverty & - & $38.1 \%$ & $79.6 \%$ \\
Subjective energy poverty & $12.3 \%$ & - & $34.1 \%$ \\
Income Poverty & $28.5 \%$ & $37.8 \%$ & - \\
\hline
\end{tabular}

by Thomson and Snell (2013) which reports 5\% of the Spanish sample with inadequate heating (against an EU average of 12\%), 5\% with utility arrears (EU average 8\%) and over $15 \%$ with issues in terms of house damp etc (EU average 18\%). As elsewhere, the prevalence of energy poverty results from the "complex interaction of low income and energy efficiency" with climatic conditions, energy prices, and individual energy needs (Healy and Clinch, 2002). Mean winter temperatures in Spain are just above the average for UK and Ireland (Healy, 2003), and while housing energy efficiency is around the EU average, the standard in the average home is far from what would be considered energy efficient (Cuchi and Sweatman, 2011). In part this may be attributed to the fact that over $50 \%$ of Spanish housing stock was constructed prior to the 1980s before housing energy efficiency was included in building regulations. Housing policy in Spain has traditionally favoured owner occupancy with a very small rental sector and negligible social housing (Pareja-Eastaway and Martin-Varo, 2002; Healy, 2003b). While this might be seen to favour household investments in energy efficiency measures, the housing stock in Spain is dominated by large multi-family dwellings, i.e. large apartment blocks where the prevalence of energy poverty is known to be generally higher (Healy and Clinch, 2002) and where energy efficiency investments may be hampered by the need for coordination across owners (Dubois, 2012). Finally, a number of policy measures in Spain e.g. social electricity tariffs, energy efficiency improvement aids, may alleviate energy poverty. However, it has not been an explicit policy objective and any impact on energy poverty has been unintended and often temporary (Tirado-Herrero et al, 2012).

Table 2 explores the relationship between the two measures of energy poverty and also between energy poverty and income poverty in our dataset, reporting the proportion of each sub-sample (expenditure energy poor, subjective energy poor, and income poverty) across all four years analysed. Not surprisingly, a high proportion (79.6 per cent) of those who are energy poor according to the expenditure-based measure are also in income poverty. The equivalent figure for those classified as subjective energy poor and also income poor is just $34.1 \%$. On the other hand, a significantly smaller proportion of those classified as income poor are also classified as energy poor according to the expenditure measure (28.5 per cent) or subjective energy poor $(37.8 \%)$. The fact the latter is the higher of the two is consistent with the view that the subjective energy poverty measure is capturing a wider aspect of energy poverty then the expenditure-based measure. Importantly, the relatively low figures in the bottom row of Table 2 suggests that policy measures targeted at income poverty will miss many of those suffering energy poverty. As in previous research (Waddams Price et al., 2012), the overlap between those classified as subjective energy poor and expenditure-based energy poor is relatively low. Thirty-eight percent of those energy poor according to the expenditure- 
TABLE 3

Average Year to Year Movements by (Energy) Poverty Measure

\begin{tabular}{|c|c|c|c|c|}
\hline & & \multicolumn{3}{|c|}{ Year $\mathbf{t}+1$} \\
\hline & & \multicolumn{3}{|c|}{ Expenditure-based energy poverty } \\
\hline & & Not Energy poor & Energy poor & $N$ \\
\hline \multirow[t]{4}{*}{ Year $\mathbf{t}$} & Not Energy poor & 94.36 & 5.64 & 14693 \\
\hline & Energy poor & 55.90 & 44.10 & 1093 \\
\hline & & \multicolumn{3}{|c|}{ Subjective energy poverty } \\
\hline & & Not Energy poor & Energy poor & \\
\hline \multirow[t]{4}{*}{ Year $\mathbf{t}$} & Not Energy poor & 84.72 & 15.28 & 12158 \\
\hline & Energy poor & 47.82 & 52.18 & 3628 \\
\hline & & \multicolumn{3}{|c|}{ Income poverty ( $<60 \%$ national median) } \\
\hline & & Above poverty line & Below poverty li & \\
\hline \multirow[t]{2}{*}{ Year $\mathbf{t}$} & Above poverty line & 90.52 & 9.48 & 12410 \\
\hline & Below poverty line & 30.63 & 69.37 & 3376 \\
\hline
\end{tabular}

based measure are classified as poor according to the subjective measure, while only $12.3 \%$ of those in subjective energy poverty are classified as energy poor according to the expenditure measure. Again this highlights the broader nature of the subjective energy poverty measure and suggests that policy measures focussed purely on reducing energy costs may not address all of the underlying issues.

\section{* 4. ENERGY POVERTY MOBILITY ̌ㅡ}

The picture presented in Table 2 is static in that it only reports the average proportions in the various poverty categories over the four-year period. It does not provide any information about movements into and out of either energy poverty or income poverty during the period. To provide an indication of these, the average rate of movement between each of the poverty classifications over the four years is presented in Table 3. These tables are generated from the matrix of transitions for each energy and income poverty category in one period to the next, i.e. they represent an estimate of the appropriate Markov transition matrix. Thus, each row represents an energy or income poverty classification for an initial time period, each column the classification for the subsequent period, with each cell the proportion on average who 'move' from one (energy) poverty category to another between periods.

For example, for the expenditure-based energy poverty measure, of individuals in the sample who in period $(t)$ were in energy poverty, on average 44.1 per cent were still in energy poverty in the next period $(t+1)$. For the subjective energy poverty measure, a slightly higher proportion on average ( 52 per cent) remained in energy poverty from year to year. For both measures there does appear to be a significant amount of mobility out of energy poverty, with 55.9 per cent of individuals using the expenditure measure and 47.8 per cent defining themselves as not energy poor in a subsequent year according to the subjective measure. In contrast, consistent with evidence from elsewhere (Jenkins and Rigg, 2001), the rate of transition out 
TABLE 4

Poverty persistence. Distribution of periods spent in energy and income poverty (\%)

\begin{tabular}{lccccc} 
& \multicolumn{5}{c}{ Number Times in Poverty in 4 Year Period } \\
\cline { 2 - 6 } & 0 & 1 & 2 & 3 & 4 \\
\hline Expenditure-based energy poverty & 80.4 & 12.1 & 4.4 & 2.2 & 0.9 \\
Subjective energy poverty & 51.1 & 21.1 & 13.0 & 9.4 & 5.3 \\
Income poverty & 62.0 & 14.1 & 8.3 & 5.7 & 9.8 \\
\hline
\end{tabular}

of the income poverty category is substantially lower (30.63 percent), than the proportion who on average remain in poverty. For those who are defined as not energy or generally poor at in $t$, it is notable that the subjective energy poverty category has the highest rate of entry into the (energy) poverty category, with 15.28 per cent moving from non-energy poor to energy poor in the next period.

Although not conclusive, we can speculate on the reasons for the observed differences in aggregate mobility between energy and income poverty. As discussed above, differences in winter temperatures or energy price changes affect energy poverty directly (and significantly) while income poverty is not affected by changes in the cost of living. Average winter temperatures in Spain were somewhat lower in the winters of 2009 and 2010 while energy prices rose over the period. ${ }^{5}$ Both might be expected to increase the rate of entry into energy poverty and decrease the rate of exit.

Differences between the dynamics of the two energy poverty measures reflect, amongst other things, differences in the pattern of energy efficiency of homes across households and differences in the ability of households to adjust their expenditure behaviour. The higher rate of entry to subjective energy poverty than expenditure energy poverty is consistent with the claim that households reduce energy expenditure in the face of energy poverty risk. Similarly, the higher exit rate for expenditure energy poverty relative to subjective energy poverty is consistent with the view that at least some households that feel energy poor respond by reducing their energy expenditure (taking them out of expenditure energy poverty).

\section{* 5. CHARACTERISTICS OF THOSE IN ENERGY POVERTY}

While Table 3 illustrates the overall mobility out of energy and general poverty, it implicitly assumes that individuals in each of the different poverty categories are identical, with equal exit and entry chances. In reality, the composition of each category is likely to be heterogeneous both in terms of characteristics and the propensities to 'escape' or remain energy or income poor. This section therefore considers in more detail the pattern of energy and general poverty and the characteristics of those who experienced (energy) poverty persistently during the fouryear period.

Table 4 provides information on the overall distribution of periods spent in energy and general poverty, including those who never experience poverty under all definitions. Consistent with previous evidence on income poverty dynamics in Spain (Arranz and Canto, 2012), the

5. Calculations based on available monthly temperatures for each December, January and February for 12 Cities in mainland Spain available from the UK Met Office. 
TABLE 5

Socio-economic characteristics of those in energy and income poverty (normalised)

\begin{tabular}{lcccc}
\hline & & $\begin{array}{c}\text { Expenditure-based } \\
\text { energy poverty }\end{array}$ & $\begin{array}{c}\text { Subjective energy } \\
\text { poverty }\end{array}$ & $\begin{array}{c}\text { Income } \\
\text { poverty }\end{array}$ \\
\hline & All sample & At least 1 period & At least 1 period & At least 1 period \\
\hline Person Type & & & & \\
$\quad$ Male working age & 37.1 & 0.83 & 1.02 & 0.82 \\
$\quad$ Female working age & 40.2 & 0.92 & 0.97 & 0.93 \\
$\quad$ Male retired & 9.9 & 1.27 & 0.95 & 1.29 \\
$\quad$ Female retired & 12.8 & 1.54 & 1.06 & 1.52 \\
Household type & & & & \\
$\quad$ Single & 6.6 & 2.19 & 1.08 & 1.95 \\
$\quad$ Two people & 24.5 & 1.32 & 0.89 & 1.17 \\
$\quad$ Three or more people & 69.0 & 0.78 & 1.03 & 0.85 \\
Individual employment status & & & & \\
$\quad$ Working & 47.8 & 0.63 & 0.92 & 0.61 \\
$\quad$ Unemployed & 7.9 & 1.57 & 1.49 & 1.60 \\
$\quad$ Retired & 18.8 & 1.18 & 0.95 & 1.16 \\
$\quad$ Inactive & 25.6 & 1.38 & 1.04 & \\
\hline
\end{tabular}

total proportion who have at least one period in (energy) poverty over the four year period is much greater than the proportion experiencing (energy) poverty in any particular period, with nearly 20 per cent for the expenditure-based measure, close to 49 per cent for the subjective measure, while around 38 per cent of individuals experience at least one period classified as living in income poverty.

There are striking differences in the proportions of individuals who are persistently energy poor or income poor. Less than 1 per cent are defined as expenditure energy poor in all four periods, for the subjective energy poverty this value increases to 5 per cent, while nearly 10 per cent of individuals are in general poverty in all four periods. The large difference between the extent of energy poverty persistence across the expenditure-based and subjective again is consistent with the argument that significant numbers of households facing energy poverty adjust their energy expenditures.

Table 5 provides more detailed information on some socio-economic characteristics of the entire sample, and of those experiencing poverty under the three alternative definitions. Characteristics are grouped into three categories: person type, household type and household economic status. Table 5 reports actual proportions for the entire sample (column 1) while the values reported in columns 2 to 4 of Table 5 are normalised values, indicating the degree to which a particular characteristic is over- or under-represented among those experiencing poverty. For example, the proportion of retired females experiencing at least one period of expenditure energy poverty was 1.54 times the proportion of retired females in the entire sample, while the proportion of retired females in the subjective energy poverty was only slightly above the proportion in the overall sample (1.06).

Many of the characteristics of those who experience expenditure energy and income poverty are similar for all measures and are consistent with previous studies for both Spain and across Europe (Healy and Clinch; 2002; OECD, 2008). For example, the results show that 
TABLE 6

Exits out of Energy and General Poverty ${ }^{\mathrm{a}}$

\begin{tabular}{|c|c|c|c|c|c|c|}
\hline \multirow[b]{2}{*}{$\begin{array}{l}\text { Time since } \\
\text { start of spell }\end{array}$} & \multicolumn{2}{|c|}{$\begin{array}{l}\text { Expenditure-based } \\
\text { energy poverty }\end{array}$} & \multicolumn{2}{|c|}{$\begin{array}{c}\text { Subjective energy } \\
\text { poverty }\end{array}$} & \multicolumn{2}{|c|}{ Income Poverty } \\
\hline & $\begin{array}{l}\text { Survivor } \\
\text { Function }\end{array}$ & Hazard & $\begin{array}{l}\text { Survivor } \\
\text { Function }\end{array}$ & Hazard & $\begin{array}{l}\text { Survivor } \\
\text { Function }\end{array}$ & Hazard \\
\hline 1 year & $\begin{array}{c}0.548 \\
(0.019)\end{array}$ & $\begin{array}{c}0.584 \\
(0.032)\end{array}$ & $\begin{array}{c}0.599 \\
(0.012)\end{array}$ & $\begin{array}{c}0.502 \\
(0.019)\end{array}$ & $\begin{array}{c}0.571 \\
(0.016)\end{array}$ & $\begin{array}{l}0.546 \\
(0.026)\end{array}$ \\
\hline 2 years & $\begin{array}{c}0.416 \\
(0.025)\end{array}$ & $\begin{array}{c}0.274 \\
(0.049)\end{array}$ & $\begin{array}{c}0.477 \\
(0.016)\end{array}$ & $\begin{array}{c}0.227 \\
(0.025)\end{array}$ & $\begin{array}{c}0.448 \\
(0.019)\end{array}$ & $\begin{array}{c}0.241 \\
(0.031)\end{array}$ \\
\hline
\end{tabular}

${ }^{a}$ Life-table estimates adjusted for discrete nature of data using all non-left censored (energy) poverty spells. Standard errors in brackets. The analysis is based on 829 expenditure-based energy poverty spells, 2032 subjective energy poverty spells and 1176 income poverty spells.

retired men and women, those in single person households and those who are inactive or unemployed are over-represented. In contrast, although many of these patterns are observed for the subjective energy poverty measure, the range is typically much less. This suggests that subjective energy poverty is much more evenly distributed across the sample than either the expenditure energy poverty or income poverty. Comparing differences between those in subjective and expenditure energy poverty suggests, not implausibly, that individuals of working age in energy poverty are more likely to adjust expenditure than retired or single person households.

The results in Table 4 emphasised the differences across individuals in terms of the time spent in energy or income poverty. Evidence from more general studies of income poverty suggest that "scarring" or duration dependence effects can be important, e.g. an individual's probability of escape from poverty reduces the longer the individual has been in the state. Such effects may also characterise the dynamics of energy poverty in which case targeted policy mechanisms may be more effective as a means of addressing problems.

Hence, to separate out the typical individual experience of mobility into (and out of) energy and income poverty from the average, we analyse spells of time spent in (and out of) energy and income poverty. The four year rotating nature of the panel data restricts the length of spells observed. Formally, the analysis below uses all spells which are not left-censored, i.e. the start of all spells is observed which means that the maximum spell length available is 3 periods. The analysis does allow for right-censored spells, i.e. where we do not know how a spell ends, but by definition the maximum non-right censored spell length in the data is 2 periods. Despite the shortness of the spells, we can undertake analysis of whether the probability of exiting energy poverty falls as time spent in energy poverty increases. Alternatively, if an individual escapes, we can explore whether the probability of re-entry changes as time out of the poverty state increases.

Table 6 reports the sample of spells of energy and income poverty which have just started and reports the adjusted life table estimates of the associated survivor and hazard functions. The survivor function is the probability that a spell which has just begun lasts for $t$ periods, while in this context the hazard can be interpreted as the conditional probability of an exit during period $t$ from a particular poverty category given the spell has lasted $t-1$ periods. The results suggest that, for all categories of poverty, the probability of exit for those who 
TABLE 7

Rates of Re-entry into Energy and General Poverty ${ }^{\mathrm{a}}$

\begin{tabular}{|c|c|c|c|c|c|c|}
\hline \multirow[b]{2}{*}{$\begin{array}{l}\text { Time since } \\
\text { start of spell }\end{array}$} & \multicolumn{2}{|c|}{$\begin{array}{l}\text { Expenditure-based } \\
\text { energy poverty }\end{array}$} & \multicolumn{2}{|c|}{$\begin{array}{c}\text { Subjective energy } \\
\text { poverty }\end{array}$} & \multicolumn{2}{|c|}{ Income Poverty } \\
\hline & $\begin{array}{l}\text { Survivor } \\
\text { Function }\end{array}$ & Hazard & $\begin{array}{l}\text { Survivor } \\
\text { Function }\end{array}$ & Hazard & $\begin{array}{l}\text { Survivor } \\
\text { Function }\end{array}$ & Hazard \\
\hline 1 year & $\begin{array}{c}0.788 \\
(0.019)\end{array}$ & $\begin{array}{c}0.237 \\
(0.032)\end{array}$ & $\begin{array}{c}0.666 \\
(0.012)\end{array}$ & $\begin{array}{c}0.402 \\
(0.017)\end{array}$ & $\begin{array}{l}0.768 \\
(0.015)\end{array}$ & $\begin{array}{l}0.263 \\
(0.026)\end{array}$ \\
\hline 2 years & $\begin{array}{c}0.694 \\
(0.024)\end{array}$ & $\begin{array}{c}0.128 \\
(0.026)\end{array}$ & $\begin{array}{c}0.524 \\
(0.014)\end{array}$ & $\begin{array}{c}0.237 \\
(0.020)\end{array}$ & $\begin{array}{c}0.664 \\
(0.019)\end{array}$ & $\begin{array}{l}0.145 \\
(0.021)\end{array}$ \\
\hline
\end{tabular}

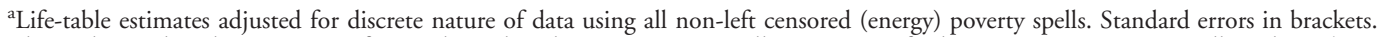
The analysis is based on 611 out of expenditure-based energy poverty spells, 1908 out of subjective energy poverty spells and 1034 out of income poverty spells.

have just started a period of energy or general poverty is relatively high in the first period ranging from 0.5 for the subjective energy poverty category to 0.58 for expenditure-based energy poverty. However, this falls by around half in the second period. From the survivor function estimates, the probability of an individual who has just started a spell of expenditurebased energy poverty still being in energy poverty after two periods is 0.416 , for subjective energy poverty 0.477 and general poverty 0.448 . Although strong conclusions are not possible using only spells of three periods, the results do suggest some "scarring" or duration dependence in energy poverty (similar to that observed in income poverty).

Table 7 reports the survivor function and hazard of re-entry to (energy) poverty for those who have just finished a spell in (energy) poverty. As in Table 6, the results provide some evidence of duration dependence effects with, in all cases, the re-entry hazard rates falling substantially if the individual spends at least one period out of poverty. However, there also appear to be a number of notable differences across the measures. While the results for the expenditure-based energy poverty measure and income poverty are broadly similar, the reentry hazards are significantly higher for the subjective energy poverty category. In particular, for an individual who has just started a spell out of subjective energy poverty, the probability of still being out of subjective energy poverty after two periods is only 0.52 compared to 0.69 and 0.66 for expenditure-based or income poverty respectively.

\section{* 5. CONCLUSIONS}

Reducing the proportion of households in energy poverty has become an increasingly important policy objective across the EU. This paper has examined the level and dynamics of energy poverty in Spain drawing on longitudinal data between 2007 and 2010. Two alternative measure of energy poverty are used in the analysis-one based on energy expenditure as a proportion of household income, the other based on an individual's self reported perceptions of difficulty heating their home, paying utility bills and housing condition.

The level of energy poverty in the sample is similar to that found in other studies with just over $10 \%$ of the sample in energy poverty according to the expenditure-based measure in 2010, and a higher proportion (28\%) in energy poverty according to the subjective selfreported measure. A high proportion (79.6\%) of those who are in expenditure-based energy 
poverty were also in income poverty at some point during the period analysed. The comparable figure for the subjective energy poverty sample was only 34.1\%. Importantly, in both cases, the proportion of those in income poverty and also in energy poverty was low suggesting that policy measures aimed exclusively at redressing income poverty will miss many of those experiencing energy poverty. Instead policies aimed directly at reducing energy poverty are required.

In relation to the dynamics of energy poverty, the proportion of the sample that can be characterized as persistently energy poor is substantially less than the proportion that is persistently income poor. In other words, at the aggregate level there is greater movement out of the energy poverty relative to income poverty. At the same time, there is evidence of duration dependence with the conditional probability of those just starting a spell of energy poverty exiting after two periods being substantially smaller than the probability of exit after one period. A similar picture arises for rates of re-entry into energy poverty, although here differences emerge across the two measures of energy poverty, with the re-entry rate of subjective energy poverty substantially higher.

Previous authors have argued that expenditure-based measures of energy poverty are too narrow because they ignore mitigating expenditure behaviour. This limits their usefulness as a means of assessing policy effectiveness. The ability to make expenditure adjustments will vary by individual and household type with older retiree households for example less likely to be able to adjust their spending on energy (or other necessities) when prices increase than younger, working households. It follows that expenditure-based measures of energy poverty may inadvertently miss certain types of individuals (e.g. those of working age) who can make expenditure adjustments but who nevertheless fall into a category of energy poor.

Consistent with previous studies, the results suggest that subjective energy poverty is more pervasive with the characteristics of the subjective energy poor closer to that of the overall sample than those classified as poor under the expenditure-based measure. As a result, policies aiming to address subjective energy poverty will need to look beyond the characteristics of the individuals to the underlying reasons why they report themselves as energy poor. In this particular analysis, poor housing conditions seemed to be the main factor giving rise to selfreported energy poverty. Individuals living in such housing are likely to perceive themselves as energy poor until the problems are addressed, confirming the need for policy measures focussed explicitly on improving the conditions of housing stock.

The observed differences in the duration of energy poverty between the two measures (expenditure-based versus subjective) has implications for tracking levels of energy poverty. The results suggest that it is harder to exit subjective energy poverty but also it is easier to enter subjective energy poverty than expenditure-based energy poverty. Therefore, tracking the success of energy policy measures on the basis of expenditure-based measures may underestimate both the extent and duration of energy poverty spells. Again the categories of household who are most likely to be overlooked are those who are able to adjust their expenditure patterns in order to either exit or avoid re-entering expenditure-based energy poverty but who, due to the condition of their homes, continue to perceive themselves as energy poor.

There are, of course, a number of caveats to the analysis which need to be emphasised. First the analysis of energy poverty dynamics would be improved through extending the number of years analysed. Similarly it would be useful to check the sensitivity of the results to the definitions of energy poverty adopted for the purpose of analysis and conduct a more in-depth analysis of household adjustments in response to exogenous changes in energy prices. 
It is possible that the results are country specific and the nature of the adjustment process may differ in other countries, particularly in Northern and Eastern Europe. This would depend, for example, on the way in which households respond to change changes in energy prices, demographic differences and differences in household composition across countries (including for example whether elderly or retiree households live with extended family) and the nature and effectiveness of the existing energy and income poverty policy measures. Notwithstanding these issues, the analysis has provided several new insights into both the relationship between energy poverty and income poverty, and the dynamics of energy poverty. These insights are useful in relation to designing and monitoring the effectiveness of energy policies.

\section{* ACKNOWLEDGMENTS}

Deborah Roberts acknowledges the support of funding from the Scottish Government's Rural and Environment Science and Analytical Services Division (RESAS). The authors would also like to acknowledge the helpful comments of the anonymous reviewers.

\section{References}

Arranz, J.M. and O. Canto (2012). "Measuring the effect of spell recurrence on poverty dynamics-evidence from Spain." Journal of Economic Inequality 10 (2):191-217. http://dx.doi.org/10.1007/s10888-011-9191-2.

Boardman, B. (1991). Fuel Poverty: from Cold Homes to Affordable Warmth. London: Belhaven Press.

Boardman, B. (2012). "Fuel Poverty Synthesis: Lessons learnt, actions needed. Energy Policy.” 49:143-148. http:// dx.doi.org/10.1016/j.enpol.2012.02.035.

Bouzarovski S. Petrova S. and R. Sarlamanov (2012). "Energy Poverty Policies in the EU: A Critical perspective.” Energy Policy 49:76-82. http://dx.doi.org/10.1016/j.enpol.2012.01.033.

Brunner, K.M. Spitzer, M. and A. Christanell (2012) "Experiencing fuel poverty. Coping strategies of low income households in Vienna/Austria.” Energy Policy 49: 53-59. http://dx.doi.org/10.1016/j.enpol.2011.11.076.

Cuchi, A. and P. Sweatman (2011). Una visión-país para el sector de la edificación en España. Hoja de ruta para un nuevo sector de la vivienda. Coordinado por el Green Building Council España y la Fundación CONAMA.

Dubois, U. (2012). "From Targeting to Implementation: The Role of Identification of Fuel Poor Households." Energy Policy 49: 107-115. http://dx.doi.org/10.1016/j.enpol.2011.11.087.

Dubois, U. (2014). La Précarité énergétique en milieu urbain : vers une analyse en termes de vulnérabilité. Working Paper Institute Supérieur de Gestion Paris

Dubois, U. and I. Mayer (2013). "Energy Poverty in France and Germany: Perceptions and Policy Approaches." International Association for Energy Economics European Conference Paper, Dusseldorf August 2013.

EC (2010). An Energy policy for Customers. Commission Staff Working Paper, EC, Brussels, 11.11.2010,.

European fuel Poverty and Energy Efficiency (EPEE) project (2009). Nuevos mecanismos para abordar la pobreza energética: propuestas de Bélgica, España, Francia, Italia y Reino Unido. EPEE project. WP4 - Deliverable 12

Healy, J.D. (2003). "Excess Winter Mortality in Europe: a cross-country analysis identifying risk factors.” Journal of Epidemiology and Community Health 57(10): 784-789. http://dx.doi.org/10.1136/jech.57.10.784.

Healy, J.D. (2003b). "Housing Conditions, Energy Efficiency, Affordability and Satisfaction with Housing: A Pan European Analysis.” Housing Studies 18(3): 409-424. http://dx.doi.org/10.1080/02673030304242.

Healy, J.D. and J.P. Clinch (2002). "Fuel poverty in Europe: A Cross-country Analysis using A new composite measure.” Working Paper Environmental Studies Research Series University College Dublin.

Healy, J.D. and J.P. Clinch (2004). "Quantifying the severity of fuel poverty, its relationship with poor housing and reasons for non-investment in energy-saving measures in Ireland”. Energy Policy 32(2): 207-220. http:// dx.doi.org/10.1016/S0301-4215(02)00265-3.

Hills, J. (2012). Getting the measure of fuel poverty Final Report of the Fuel Poverty Review CASE report 72, Department of Energy and Climate Change (DECC), London 
Howieson, S.G. (2005). Multiple deprivation and excess winter deaths in Scotland. Journal for the Royal Society for the Promotion of Health 125 (1): 18-22. http://dx.doi.org/10.1177/146642400512500110.

INE (2012). Encuesta de Condiciones de Vida, Año 2012. Datos provisionales. Press Release, Survey on Living Conditions for Spain. www.ine.es/prensa/np740.pdf, accessed on 9 September 2013.

Jenkins, S.P. (2003). Survival Analysis, Published Lecture Notes. Institute for Social and Economic Research, University of Essex Summer School. University of Essex.

Liddell, C. and C. Morris. (2010). "Fuel poverty and human health: a review of recent evidence." Energy Policy 38 (6): 2987-2997. http://dx.doi.org/10.1016/j.enpol.2010.01.037.

Liddell, C. Morris, C., McKenzie, S.J.P and G. Rae (2012) "Measuring and monitoring fuel poverty in the UK: National and regional perspectives." Energy Policy 38 (49): 27-32. http://dx.doi.org/10.1016/j.enpol.2012. 02.029 .

Moore, R. (2012). "Definitions of fuel poverty: Implications for policy." Energy Policy 49: 19-26. http://dx.doi.org/ 10.1016/j.enpol.2012.01.057.

Jarvis, S. and S.P. Jenkins (1997). "Low income dynamics in 1990s Britain.” Fiscal Studies, 18 (2):123-142. http:// dx.doi.org/10.1111/j.1475-5890.1997.tb00257.x.

Jenkins S.P. and J. Rigg (2001). The Dynamics of Poverty in Britain. Department of Work and Pensions Research Report No 157. HMSO.

Morrison, C. and N. Shortt (2008). "Fuel poverty in Scotland: Refining spatial resolution in the Scottish Fuel Poverty Indicator using a GIS-based multiple risk index." Health and Place 14 (4):702-717. http://dx.doi.org/ 10.1016/j.healthplace.2007.11.003.

OECD (2008). Growing Unequal ? Income Distribution and Poverty in OECD Countries. Paris: OECD.

OECD (2011). Divided We Stand -Why Inequality Keeps Rising. Paris: OECD. www.oecd.org/social/inequality.htm /www.oecd.org/fr/social/inegalite.htm.

O’Higgins, M. Schmaus, G. and G. Stephenson (1990). "Income poverty in seven countries." in Smeeding, T. O'Higgins, M And Rainwater, L (eds.) Poverty, inequality and income distribution in comparative perspective, Washington: The Urban Institute.

Pachauri, S. and D. Spreng (2004) "Energy Use and Energy Access in Relation to Poverty." Economic and Political Weekly 39(3): 17-23.

Eastaway, M.P. and M. Varo (2002). "The Tenure Imbalance in Spain: The Need for Social Housing Policy." Urban Studies 39: 283-295. http://dx.doi.org/10.1080/00420980120102975.

Phimister, E. Upward, R. and E. Vera-Toscano (2000). The Dynamics of Low Incomes in Rural Areas, Regional Studies 34 (5): 407-417. http://dx.doi.org/10.1080/00343400050058666.

Piachaud, D. (1993). The definition and measurement of poverty and inequality in Barr, N. Whynes, D. (eds.) Current Issues in the Economics of Welfare, London: Macmillan.

Stevens, A. (1999). "Climbing out of poverty. Falling back in: measuring the persistence of poverty over multiple spells.” Journal of Human Resources, 3: 557-588. http://dx.doi.org/10.2307/146380.

Thomson, H. and C. Snell (2013) Quantifying the prevalence of fuel poverty across the European Union, Energy Policy. 52:563-572. http://dx.doi.org/10.1016/j.enpol.2012.10.009.

Tirado Herrero, S. López Fernández, J.L. and P. Martín García (2012a). Pobreza energética en España, Potencial de generación de empleo directo de la pobreza derivado de la rehabilitación energética de viviendas. Madrid : Asociación de Ciencias Ambientales.

Tirado Herrero, S. López Fernández, J.L. and S. Mancheño Losa (2012b). "Fuel Poverty And Unemployment In Spain.” Paper IAAE Conference Paper Venice September 2012).

Townsend, P. (1979). Poverty in the United Kingdom: a survey of household resources and standards of living, Middlesex: Penguin.

Waddams Price, C. Brazier, K. and W.Wang (2012). Objective and Subjective Measures of Fuel Poverty Energy Policy 49: 33-39. 